Article (refereed)

Tipping, Edward; Corbishley, Heather T.; Koprivnjak, Jean-Francois; Lapworth, Daniel J.; Miller, Matthew P.; Vincent, Colin D.; Hamilton-Taylor, John. 2009 Quantification of natural DOM from UV absorption at two wavelengths. Environmental Chemistry, 6 (6). 472-476. 10.1071/EN09090

(c) CSIRO 2009

This version available http://nora.nerc.ac.uk/9071/

NERC has developed NORA to enable users to access research outputs wholly or partially funded by NERC. Copyright and other rights for material on this site are retained by the authors and/or other rights owners. Users should read the terms and conditions of use of this material at http://nora.nerc.ac.uk/policies.html\#access

This document is the author's final manuscript version of the journal article, incorporating any revisions agreed during the peer review process. Some differences between this and the publisher's version remain. You are advised to consult the publisher's version if you wish to cite from this article.

www.publish.csiro.au 
Submitted to Environmental Chemistry / Rapid Communication / October 2009

\section{Quantification of natural DOM from UV Absorption at Two}

\section{Wavelengths}

Edward Tipping ${ }^{a}$, Heather T. Corbishley ${ }^{a}$, Jean-Francois Koprivnjak ${ }^{\mathrm{b}}$, Daniel J. Lapworth ${ }^{\mathrm{c}}$, Matthew P. Miller ${ }^{d}$, Colin D. Vincent ${ }^{\mathrm{a}}$ \& John Hamilton-Taylor ${ }^{\mathrm{e}}$

${ }^{a}$ Centre for Ecology and Hydrology, Lancaster Environment Centre, Bailrigg, Lancaster LA1 4AP, United Kingdom

${ }^{\mathrm{b}}$ Environmental and Resource Studies Program, Trent University, Canada

c British Geological Survey, Maclean Building, Wallingford, Oxfordshire, OX10 8BB, United Kingdom

${ }^{\mathrm{d}}$ Department of Civil, Environmental, and Architectural Engineering, Institute of Arctic and Alpine Research, University of Colorado, Boulder, USA

e Lancaster Environment Centre, Lancaster University, Lancaster, LA1 4YQ, United

Kingdom

Correspondence to: $\quad$ Professor Edward Tipping

Centre for Ecology and Hydrology

Lancaster Environment Centre

Lancaster

LA1 4AP

United Kingdom 
34 Environmental Context. Dissolved organic matter (DOM) is part of the global carbon cycle, ecologically and geochemically active, and costly to remove in water treatment. Spectroscopic monitoring at a single wavelength provides some indication of DOM concentration, but variations in optical properties mean that accurate determinations currently rely on slow and costly laboratory methods. We show that for water samples containing non-anthropogenic DOM, ultraviolet absorbance at two wavelengths can quantify DOM rapidly, cheaply and accurately, and also indicate its quality. 
Abstract. A two-component model permitted the precise simulation of ultraviolet absorption by 23 contrasting surface-water DOM samples. Although a unique set of model parameters could not be established, the results could still be used to predict [DOC] in water samples simply from absorbance values at two wavelengths (we used 254 and $340 \mathrm{~nm}$ ). The parameterised model was used to predict [DOC] for a separate dataset obtained by combining results for 12 samples each from a UK river draining upland pasture, UK groundwaters from a range of formations, stream and lake waters from a forested region of Ontario, and high-altitude alpine and subalpine streams from colorado. A close correlation $\left(R^{2}=0.997\right)$ was obtained, with only slight underestimation of the true [DOC]. Precise prediction of [DOC] from absorbance data at a single wavelength was not possible, because of differences in DOM extinction coefficients among the samples. When the model was applied to samples collected from river locations in a heterogeneous UK catchment with areas of industry and high human population, $[\mathrm{DOC}]$ was underestimated in many cases, which may indicate the presence of non-absorbing pollutant DOM.

Keywords. dissolved organic carbon - dissolved organic matter - two-component model - UV spectra

Dissolved organic matter (DOM) is a ubiquitous collection of components in surface, soil and ground waters, comprising the partial decomposition products of living material, chiefly plants and algae, but also derived from agricultural, industrial and domestic human activities. Differences in source material and rates of decomposition, and physical fractionation processes, generate substantial heterogeneity in DOM concentrations and properties. DOM participates in many ecological and geochemical reactions, and is costly to remove from water intended for domestic and industrial supply. Interest in the formation and transport of DOM has intensified because of widespread increases in DOC concentrations and fluxes seen over recent years ${ }^{[1]}$, with possible links to changes in the terrestrial carbon cycle. Routine methods for the accurate determination of DOM in different samples are based on the measurement of DOC, usually after conversion to $\mathrm{CO}_{2}$. This requires the return of samples to the laboratory, and is both time-consuming and fairly expensive. Optical absorbance at a single wavelength in the UV-visible range usually correlates strongly with [DOC], and is therefore often used to monitor natural DOM. However, differences in DOM properties among waters, and temporally within a given water, mean that this can only be an approximate method. Indeed, variation in the ratio of absorbance to [DOC] is widely used to characterise the quality of DOM, notably through the specific UV absorbance at $254 \mathrm{~nm}$ (SUVA ${ }^{[2]}$. 
The measure of optical properties used here is the extinction coefficient ( $E$; also referred to as specific absorbance and specific absorptivity) obtained as the ratio of optical absorbance at a given wavelength $(\boldsymbol{\lambda} \mathrm{nm})$ to $[D O C]$, and with units of $\mathrm{I} \mathrm{g}^{-1} \mathrm{~cm}^{-1}$. Thacker et al. ${ }^{[3]}$ determined the extinction coefficients of 23 concentrated samples of DOM from a variety of surface waters in northern England. They demonstrated a monotonic increase of the $E_{340} / E_{254}$ ratio with $E_{340}$ (Figure 1 ), which suggests that [DOC] can be deduced from absorbance data alone, by the following argument. For a given water sample, the $E_{340} / E_{254}$ ratio is exactly the same as the ratio of optical absorbances $A_{340} / A_{254}$ since both measurements refer to the same $[D O C]$. Therefore the $A_{340} / A_{254}$ ratio of the sample corresponds to a single value of $E_{340}$, which can be divided into $A_{340}$ to obtain [DOC]. If the monotonic relationship of Figure 1 applies generally, optical absorbance values at two wavelengths offer a means to estimate [DOC] accurately, despite variations in sample extinction coefficients at the individual wavelengths.

In fact, the relationship in Figure 1 is expected for a two-component system. The extinction coefficient at any wavelength is given by

$$
E_{\lambda}=f_{A} E_{\lambda, A}+f_{B} E_{\lambda, B}=f_{A} E_{\lambda, A}+\left(1-f_{A}\right) E_{\lambda, B}
$$

where $f_{A}$ and $f_{B}$ are the fractions of components $A$ and $B\left(f_{A}+f_{B}=1\right)$. For the 23 samples studied by Thacker et al. ${ }^{[3]}$ there are 46 versions of this equation if two wavelengths are considered, and 23 values of $f_{A}$. We treated the $f_{A}$ values and the four extinction coefficients as adjustable parameters, and used Microsoft Excel Solver to optimise them by minimizing the sum of the squares of $\left(E_{\lambda, \text { obs }}-E_{\lambda, \text { calc }}\right) / E_{\lambda, \text { obs. }}$. Excellent fits could be obtained, with average differences between observed and calculated values < $2 \%$, thereby supporting the two-component hypothesis. However, the model is overparameterised and so a unique parameter set cannot be obtained from this relatively small data set.

We constrained the model by specifying the value of $E_{254, A}$ to be $60 \mathrm{I} \mathrm{g}^{-1} \mathrm{~cm}^{-1}$ (equivalent to $6.0 \mathrm{I} \mathrm{mg}^{-1} \mathrm{~m}^{-1}$ in commonly used SUVA units). This can be justified from the SUVA values of isolated $\mathrm{DOM}^{[2]}$ and from the results of streamwater surveys at a variety of locations ${ }^{[3-8]}$. In none of these reports is a SUVA value exceeding $6.0 \mathrm{I} \mathrm{mg}^{-1} \mathrm{~m}^{-1}$ reported, although values exceeding $5.0 \mathrm{I} \mathrm{mg}^{-1} \mathrm{~m}^{-1}$ are not uncommon ${ }^{[3,4,7,8]}$. Therefore we can make the reasonable approximation that an $E_{254}$ value of $60 \mathrm{I} \mathrm{g}^{-1} \mathrm{~cm}^{-1}$ represents an end-member, i.e. the sample in question is entirely component $A$. Refitting the model with $E_{254, A}$ set to $60 \mathrm{I} \mathrm{g}^{-1} \mathrm{~cm}^{-1}$, and using data for three wavelengths $(254,280,340 \mathrm{~nm}$ ) to increase the ratio of observations to parameters, reduced the range of parameter sets that fitted the model. Consistent values of $E_{254, A}, E_{280, A}$ and $E_{340, A}$ were now obtained, but ranges of values of $E_{254, B}, E_{280, B}$ and $E_{340, B}$, combined with different sets of $f_{A}$ values, gave equally good fits. The same goodness-of-fit was obtained for any value of $E_{254, B}$ in the 
range 14 to $22 \mathrm{I} \mathrm{g}^{-1} \mathrm{~cm}^{-1}$, since the other model parameters could change to compensate (Table 1). Outside this range of $E_{254, B}$ however, the fits were always worse. Although fixing $E_{254, A}$ reduces the parameter ranges that can fit the data, the prediction of [DOC], (see below), is not affected. However, constraining the parameters to physically realistic values may lead to useful correlations with other DOM physico-chemical properties.

Any of the sets of extinction coefficients shown in Table 1, or indeed any intermediate set, can be used to compute $f_{A}$ in a new water sample from the following equation, obtained by combining the versions of equation (1) for each wavelength;

$$
f_{A}=\left(E_{\lambda 1, B}-R E_{\lambda 2, B}\right) /\left(R E_{\lambda 2, A}-R E_{\lambda 2, B}-E_{\lambda 1, A}+E_{\lambda 1, B}\right)
$$

where $R$ is the ratio of optical absorbance values $\left(A_{\lambda_{1}} / A_{\lambda_{2}}\right)$ for the sample in question. The value of $f_{A}$ can be substituted into equation (1) to obtain $E_{\lambda 1}$ and $E_{\lambda 2}$ for the sample, which can then be divided into either $A_{\lambda 1}$ or $A_{\lambda 2}$ respectively to obtain [DOC].

We used $E_{254, A}, E_{254, B} E_{340, A}$ and $E_{340, B}$ to predict [DOC] for a set of 48 data assembled from the results of monitoring by four separate research organisations. The field locations were judged to be free of local anthropogenic influences, and none of the samples was noticeably turbid. Samples from the River Tarnbrook were collected by the Centre for Ecology and Hydrology as part of a river monitoring programme on the RibbleWyre catchment of north-west England (see below). The river drains an area of upland pasture with low human population. The water samples were passed through whatman GF/F glass-fibre filters $(0.7 \mu \mathrm{m}$ nominal size cut-off), concentrations of DOC were determined by a combustion method using a Shimadzu TOC-VCPH instrument, and absorption spectra were measured with an Agilent 8453 diode array instrument. The British Geological Survey collected groundwater samples from piezometers or where they emerged as springs from formations in the UK. Samples for DOC and absorbance analysis were filtered using silver filters $\left(0.45 \mu \mathrm{m}\right.$ Millipore $\left.{ }^{\mathrm{TM}}\right)$ and analysed using a Thermalox ${ }^{\mathrm{TM}} \mathrm{C}$ analyser after acidification and sparging (DOC) and a $\operatorname{Varian}^{\mathrm{TM}}$ spectrophotometer (optical absorbance). Trent University collected stream and lake samples from a forested region of the Precambrian Shield in Ontario; the data used here refer to November 2007. Samples were filtered with Millipore ${ }^{\mathrm{TM}} 0.45 \mu \mathrm{m}$ membrane filters, and analysed for DOC (Shimadzu TOC-VPH) and optical absorbance (Cary 59 UV/Vis spectrophotometer). Colorado samples were collected from alpine and subalpine stream sites in the Green Lakes Valley and adjacent Como Creek watershed. The Green Lakes Valley is part of the Niwot Ridge Long Term Ecological Research (NWTLTER) site and is not influenced by direct human impacts. Samples were filtered with Whatman GF/F glass-fibre filters $(0.7 \mu \mathrm{m}$ nominal pore size), DOC was measured by high temperature catalytic oxidation with a Shimadzu 5050A TOC analyzer, and absorption spectra were measured on an Agilent 8453 UV-visible spectroscopy system. Twelve data points were 
used for each sub-set, this being the total available for the River Tarnbrook; values from the other sub-sets were chosen at random.

Values of $A_{254}$ and $A_{340}$ for each sample were used to calculate $f_{A}$ from equation (2) using calibrated extinction coefficients, then the overall sample extinction coefficients $E_{\lambda}$ were calculated with equation (1), and $[D O C]$ obtained from the ratio $A_{254} / E_{254}$. Indistinguishable results were obtained whichever of the three parameter sets of Table 1 was used. The model predicted [DOC] well (Figure 2), with $\mathrm{R}^{2}=0.997$ and a root-meansquared-deviation (RMSD) of $0.7 \mathrm{mg} \mathrm{l}^{-1}$. The slope of 0.98 and intercept of $-0.3 \mathrm{mg} \mathrm{l}^{-1}$ (significant at $\mathrm{p}<0.01$ ) result in slight underestimation of [DOC] on average, and a proportionately greater error at low [DOC]. The calculated values of $\mathrm{f}_{A}$ differed among the sub-sets; with $E_{254, B}$ set to $18 \mathrm{I} \mathrm{g}^{-1} \mathrm{~cm}^{-1}$, the averages were 0.86 for the River Tarnbrook, 0.18 for the groundwaters, 0.42 for the Ontario samples, and 0.46 for the Colorado samples. Of course the absolute $f_{A}$ values depend upon the choice of $E_{254, B}$, but their relative order is always the same.

An important feature of the data sub-sets is that they differ appreciably in their extinction coefficients at a single wavelength. For each sub-set there is quite a strong correlation of $A_{254}$ with [DOC] (Figure 2), but the slopes and intercepts differ noticeably; the results are still more divergent at $340 \mathrm{~nm}$. Use of the $A_{254}$ regression for the full data set $\left(\mathrm{R}^{2}=0.955\right)$ to predict [DOC] produces an RMSD of $1.86 \mathrm{mg} \mathrm{l}^{-1}$, more than twice the value from the two-component model.

A study by $\mathrm{CEH}$ and Lancaster University of the catchments of the Rivers Ribble and Wyre has involved fortnightly sampling of 26 representative river sites (including the River Tarnbrook site of Figure 2) in north-west England. The total catchment area of $1920 \mathrm{~km}^{2}$ has a wide range of agricultural land-uses, including pasture, arable and upland moorlands. There are also several intensely urban locations in the main towns of Accrington, Blackburn and Burnley, as well as considerable current industrial activity and the legacy of past heavy industry. We analysed 251 samples collected over the period October 2008 to February 2009, using the methods described above for the River Tarnbrook. As shown by Figure 3, the model underestimates [DOC] in many cases, but there are only two significant overestimates, and even these are probably outliers. The fact that the cloud of data points has a well-defined upper edge that corresponds to the $1: 1$ line suggests that the model provides good estimates of "natural" [DOC] but, inevitably, fails to predict concentrations of non-absorbing DOM produced by human activities. From the results, excluding likely outliers, the average non-absorbing [DOC] is $1.3 \mathrm{mg} \mathrm{l}^{-1}$, with a $5 / 95$ percentile range of $0.2 / 3.3 \mathrm{mg} \mathrm{l}^{-1}$. Note that interference by nitrate, the most common non-DOM chromophoric compound in surface waters ${ }^{[9]}$, is unlikely to be serious in these samples, since the highest nitrate concentration in these 
waters is c. $7 \mathrm{mg} \mathrm{l}^{-1}$, which would add less than $0.5 \mathrm{mg} \mathrm{l}^{-1}$ to [DOC] estimated spectroscopically. The three parameter sets of Table 1 gave nearly identical results.

The spectral analysis described here is a simple idea that has apparently not been proposed before, although there are some relevant reports. Mattson et al. ${ }^{[10]}$ used absorbance at $546 \mathrm{~nm}$ to correct values at $254 \mathrm{~nm}$ for turbidity. Simonsson et al. ${ }^{[11]}$ performed Principal Components Analysis on absorbance data in the range 210-300 nm to estimate [DOC] and [nitrate] in different forest floor leachates, but the samples did not vary greatly in DOM quality and so a generally-applicable model was not derived. Downing et al. ${ }^{[12]}$ used absorbance data only in the visible range $(412-715 \mathrm{~nm})$ to derive a statistical model for samples from a tidal wetland, but this covered only a small range of [DOC] $\left(2.4-4.0 \mathrm{mg} \mathrm{l}^{-1}\right)$ and again the range of DOM quality would have been limited. The book edited by Thomas \& Burgess ${ }^{[9]}$ devotes a chapter to the UV-visible spectroscopy of natural waters ${ }^{[13]}$ which considers "humic like substances" (equivalent to the DOM that we are interested in) and recognises variations in their UV-visible spectra, but does not discuss their absolute quantification from multi-wavelength data. Therefore we believe that ours is a novel approach.

Our method is a significant improvement over single-wavelength monitoring, since it can provide accurate estimates of [DOC] for samples with differing DOM quality, at least in natural waters not highly impacted by anthropogenic activities. The non-zero intercept when [DOC] predictions are regressed against conventionally-measured values (Figure 2) leads to reduced accuracy for samples with low $[D O C]$, which tend to be dominated by DOM with weak light absorption, but for $[\mathrm{DOC}]>$ c. $2 \mathrm{mg} \mathrm{l}^{-1}$ spectroscopic data alone can be used to determine both concentration and quality rapidly and cheaply. The true detection limit of the dual-wavelength method remains to be established, in part because of inevitable uncertainty in conventionally-determined [DOC]. These findings could significantly widen the scope of DOM research in both the laboratory and the field, including the possibility of continuous monitoring in situ, if turbidity influences could be taken into account. For polluted waters, the model does not provide good estimates of total $[\mathrm{DOC}]$ but may prove useful in distinguishing natural and pollutant DOM. The method should be tested on a wider range of DOM and water types, and there is clearly a need to improve the parameterisation, to define component $B$ in particular; as noted above, this might lead to useful correlations with DOM physico-chemical properties. We also need to understand why a simple two-component model appears to account so well for the complex mixture of compounds that constitute natural DOM. 


\section{Acknowledgements}

We thank the staff of the CEH Analytical Chemistry Laboratory and the BGS Wallingford Laboratory for assistance in sampling and analysis, and Peter Dillon, Chris Evans, Donald Monteith, Philip Rowland and Andrew Scott for helpful discussions. We are indebted to an anonymous reviewer for pointing out our initial over-parameterisation of the model; their remarks led to a significant improvement in the final paper. This work was funded in the UK by the Natural Environment Research Council (NERC), in Canada by an NSERC Strategic Grant and is published with the permission of the Director British Geological Survey (NERC).

\section{References}

[1] Monteith, D.T., Stoddard, J.L., Evans, C.D., de Wit, H.A., Forsius, M., Høgåsen, Wilander, A., Skjelkvåle, Jeffries, D.S., Vuorenmaa, J., Keller, B., Kopácek and Vesely, J. (2007) Dissolved organic carbon trends resulting from changes in atmospheric deposition chemistry. Nature, 450, 537-541.

[2] Weishaar JL, Aiken GR, Bergamaschi BA, Fram MS, Fujii R, Mopper K. (2003) Evaluation of specific ultraviolet absorbance as an indicator of the chemical composition and reactivity of dissolved organic carbon. Environ. Sci. Technol. 37: 4702-4708.

[3] Thacker, S.A., Tipping, E., Gondar, D., Baker, A. (2008) Functional properties of DOM in a stream draining blanket peat. Sci. Tot. Environ., 407, 566-573.

[4] Hood, E., Williams, M.W., McKnight, D.M. (2005) Sources of dissolved organic matter (DOM) in a Rocky Mountain stream using chemical fractionation and stable isotopes. Biogeochem. 74, 231-255.

[5] Striegl, R.G., Dornblaser, M.M., Aiken, G.R., Wickland, K.P., Raymond, P.A. (2007) Carbon export and cycling by the Yukon, Tanana, and Porcupine rivers, Alaska, 2001-2005. Water Resour. Res. 43, W02411, doi:10.1029/2006WR005201.

[6] Moore, T.R., Calrkson, B.R. (2007) Dissolved organic carbon in New Zealand peatlands. N.Z. J. Mar. Freshwat. Res., 41, 137-141.

[7] Balcarczyk, K., Jones, K.J., Jaffé, R., Maie, N. (2009) Stream dissolved organic matter bioavailability and composition in watersheds underlain with discontinuous permafrost. Biogeochem., 94, 255-270.

[8] Temnerud, J., Düker, A, Karlsson, S, Allard, B., Köhler, S., Bishop, K. (2009) Landscape scale patterns in the character of natural organic matter in a Swedish boreal stream network. Hydrol. Earth Syst. Sci., 13, 1567-1582. 
[9] Thomas O, Burgess C 2007; UV-Visible Spectrophotometry of Water and Wastewater, Elsevier.

[10] Mattson, J.S., Smith, C.A., Jones, T.T., Gerchakov, S.M. (1974) Continuous monitoring of dissolved organic matter by UV-visible photometry. Limnol. Oceanogr. 19, 530-535.

[11] Simonsson, M., Kaiser, K., Danielsson, R., Andreux, F., Ranger, J. (2005)

[12] Downing, B.D., Boss, E., Bergamaschi, B.A., Fleck, J.A., Lionberger, M.A., Ganju,

[13] Pouet MF, Theraulaz F, Mesnage V, Thomas O 2007 Natural water, in Thomas O, Burgess C 2007; UV-Visible Spectrophotometry of Water and Wastewater, Elsevier. 
280 Table 1 Fitting results for the two-component model. Parameter values in bold were fixed, those in italics are fitted. Within the precision shown, exactly the same calculated values were obtained with each of the three parameter sets.

283

284

\begin{tabular}{cccc}
\hline \multicolumn{4}{c}{ Parameters } \\
\hline$E_{254, \mathrm{~A}}$ & $\mathbf{6 0}$ & $\mathbf{6 0}$ & $\mathbf{6 0}$ \\
$\mathrm{E}_{280, \mathrm{~A}}$ & 49 & 49 & 49 \\
$\mathrm{E}_{340, \mathrm{~A}}$ & 23 & 23 & 23 \\
& & & \\
$\mathrm{E}_{254, \mathrm{~B}}$ & $\mathbf{1 4}$ & $\mathbf{1 8}$ & $\mathbf{2 2}$ \\
$\mathrm{E}_{280, \mathrm{~B}}$ & 8 & 11 & 15 \\
$\mathrm{E}_{340, \mathrm{~B}}$ & 0 & 2 & 4
\end{tabular}

$\mathrm{f}_{\mathrm{A}} \quad \mathrm{f}_{\mathrm{A}} \quad \mathrm{f}_{\mathrm{A}}$

$\begin{array}{lll}0.19 & 0.12 & 0.02\end{array}$

$\begin{array}{lll}0.24 & 0.16 & 0.07\end{array}$

$\begin{array}{lll}0.27 & 0.20 & 0.12\end{array}$

$\begin{array}{lll}0.28 & 0.21 & 0.13\end{array}$

$\begin{array}{lll}0.29 & 0.23 & 0.14\end{array}$

$\begin{array}{lll}0.31 & 0.24 & 0.16\end{array}$

$\begin{array}{lll}0.33 & 0.26 & 0.19\end{array}$

$\begin{array}{lll}0.35 & 0.29 & 0.21\end{array}$

$\begin{array}{lll}0.32 & 0.25 & 0.17\end{array}$

$\begin{array}{lll}0.40 & 0.34 & 0.27\end{array}$

$\begin{array}{lll}0.47 & 0.42 & 0.36\end{array}$

$\begin{array}{lll}0.47 & 0.42 & 0.35\end{array}$

$\begin{array}{lll}0.55 & 0.51 & 0.46\end{array}$

$\begin{array}{lll}0.60 & 0.56 & 0.51\end{array}$

$\begin{array}{lll}0.68 & 0.65 & 0.62\end{array}$

$\begin{array}{lll}0.76 & 0.74 & 0.71\end{array}$

$\begin{array}{lll}0.75 & 0.73 & 0.70\end{array}$

$\begin{array}{lll}0.79 & 0.77 & 0.74\end{array}$

$\begin{array}{lll}0.79 & 0.78 & 0.75\end{array}$

$\begin{array}{lll}0.78 & 0.76 & 0.74\end{array}$

$\begin{array}{lll}0.82 & 0.80 & 0.78\end{array}$

$\begin{array}{lll}0.79 & 0.77 & 0.75\end{array}$

0.90

0.89

\begin{tabular}{|c|c|c|c|c|c|}
\hline \multicolumn{3}{|c|}{ Calculations } & \multicolumn{3}{|c|}{ Observations } \\
\hline$E_{254}$ & $E_{280}$ & $E_{340}$ & $E_{254}$ & $E_{280}$ & $E_{340}$ \\
\hline 22.9 & 15.8 & 4.7 & 23.3 & 15.4 & 4.7 \\
\hline 24.8 & 17.5 & 5.6 & 24.8 & 17.7 & 5.6 \\
\hline 26.4 & 19.0 & 6.4 & 26.0 & 19.1 & 6.5 \\
\hline 27.0 & 19.5 & 6.7 & 26.2 & 19.4 & 6.8 \\
\hline 27.5 & 19.9 & 7.0 & 26.9 & 19.9 & 7.1 \\
\hline 28.1 & 20.5 & 7.3 & 28.0 & 20.5 & 7.3 \\
\hline 29.1 & 21.4 & 7.8 & 28.3 & 21.2 & 8.0 \\
\hline 30.0 & 22.2 & 8.2 & 30.5 & 22.7 & 8.1 \\
\hline 28.5 & 20.9 & 7.5 & 30.6 & 22.2 & 7.1 \\
\hline 32.4 & 24.3 & 9.4 & 32.5 & 24.4 & 9.4 \\
\hline 35.5 & 27.2 & 11.0 & 34.5 & 26.2 & 11.6 \\
\hline 35.4 & 27.1 & 11.0 & 37.1 & 27.0 & 10.8 \\
\hline 39.5 & 30.7 & 13.0 & 39.2 & 30.4 & 13.2 \\
\hline 41.5 & 32.5 & 14.0 & 42.5 & 32.9 & 13.7 \\
\hline 45.5 & 36.1 & 16.1 & 45.8 & 35.8 & 16.1 \\
\hline 48.9 & 39.2 & 17.8 & 47.7 & 38.8 & 18.4 \\
\hline 48.5 & 38.9 & 17.6 & 49.0 & 39.1 & 17.4 \\
\hline 50.1 & 40.3 & 18.4 & 49.2 & 40.0 & 18.8 \\
\hline 50.6 & 40.7 & 18.6 & 49.7 & 40.4 & 19.0 \\
\hline 49.9 & 40.1 & 18.3 & 50.7 & 40.8 & 17.9 \\
\hline 51.6 & 41.6 & 19.2 & 50.9 & 41.4 & 19.5 \\
\hline 50.4 & 40.6 & 18.6 & 52.2 & 41.4 & 17.9 \\
\hline 55.2 & 44.8 & 21.0 & 55.0 & 44.9 & 21.1 \\
\hline
\end{tabular}




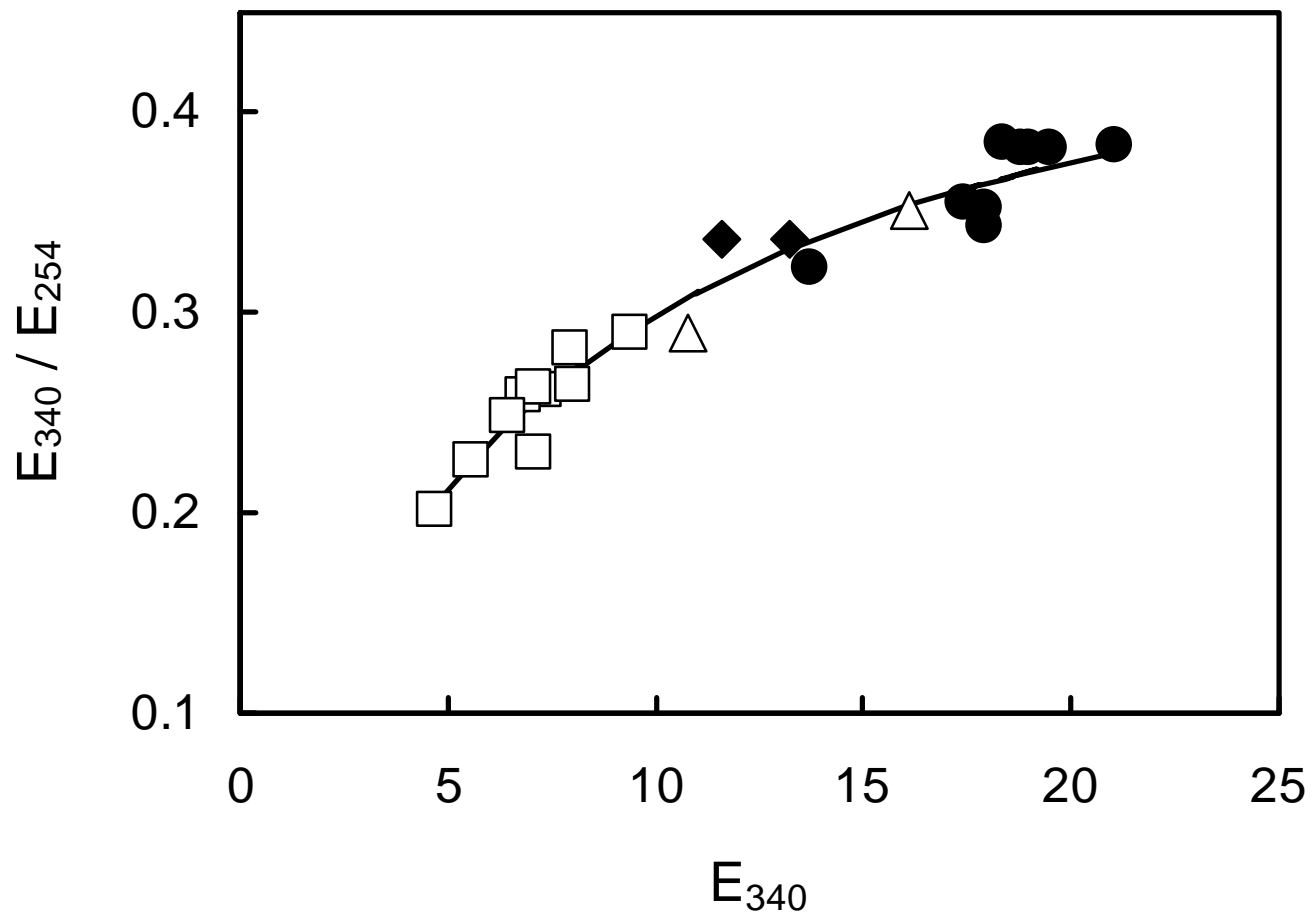

Figure 1. Relationship between the ratio of extinction coefficients at 340 and $254 \mathrm{~nm}$ and the extinction coefficient at $340 \mathrm{~nm}$ for 23 samples of DOM from four differing waters collected at different times. Key to symbols: squares, eutrophic lake; triangles and diamonds, two streams draining mineral soils; circles, peatland stream. The line is calculated from the model output shown in Table 1. 

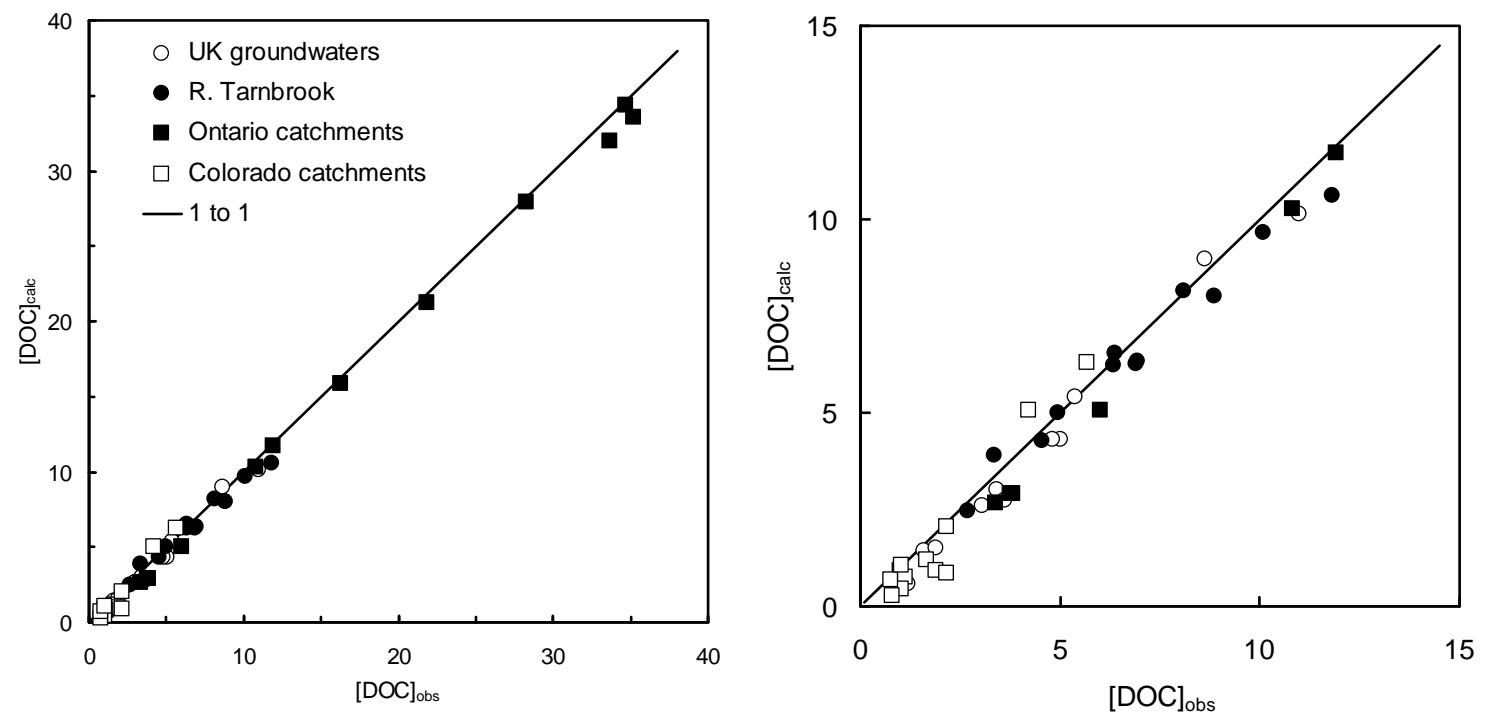

321

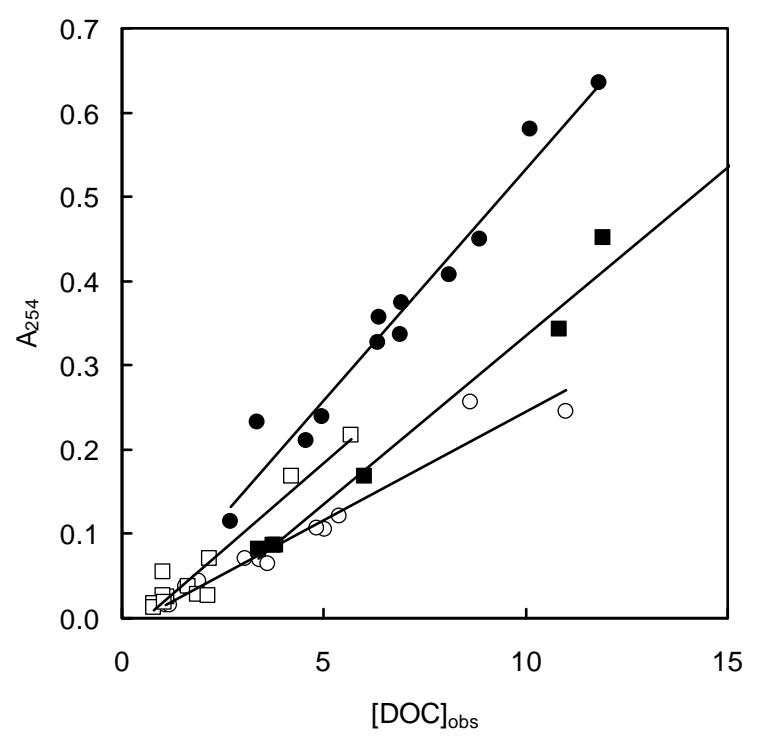

Figure 2. Predicted vs observed [DOC] in $\mathrm{mg} \mathrm{l}^{-1}$ for samples of UK groundwaters (open circles), River Tarnbrook (closed circles), Ontario sites (closed squares) and scales. Panel (c) shows the contrasting relationships between $A_{254}$ and [DOC] for the different sub-sets of samples, in the low concentration range. 


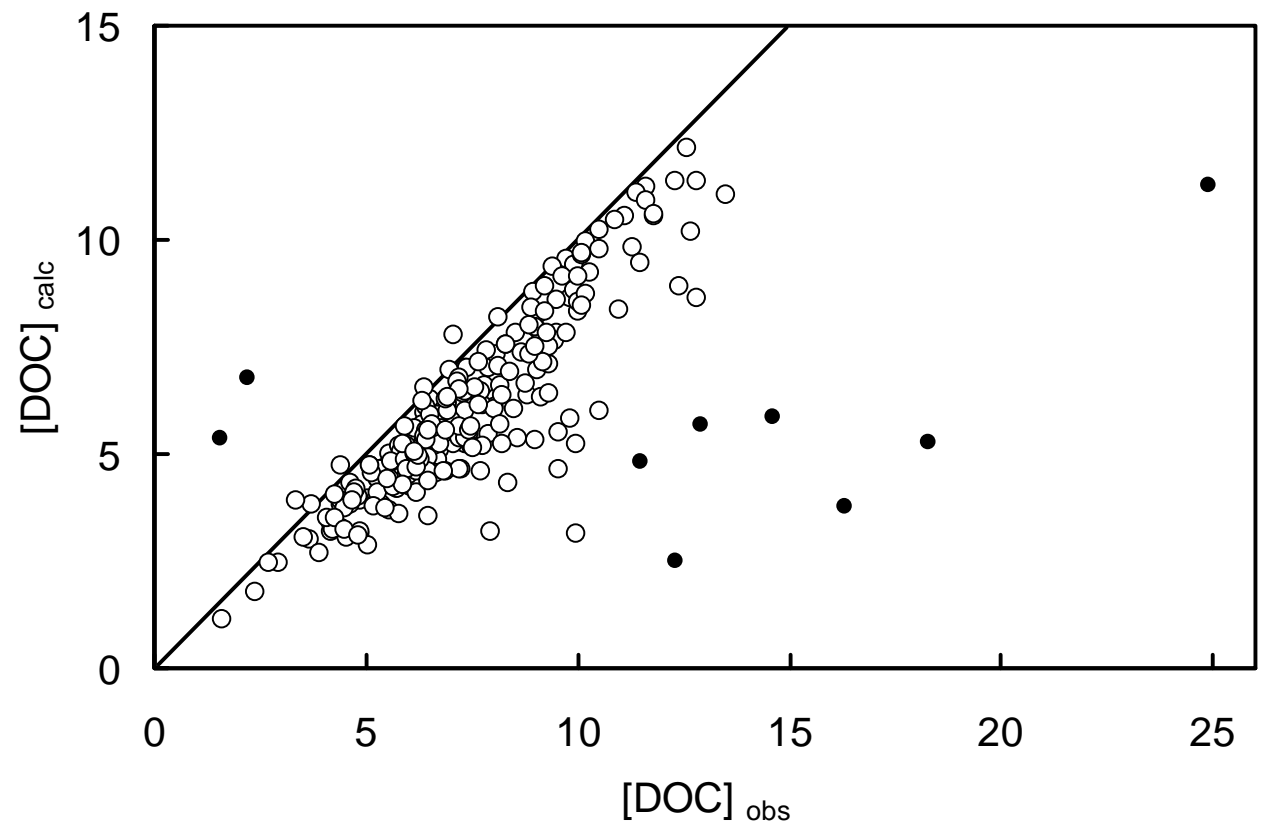
catchment, 9 or 10 points for each. The 9 filled circles are judged to be outliers, by 